
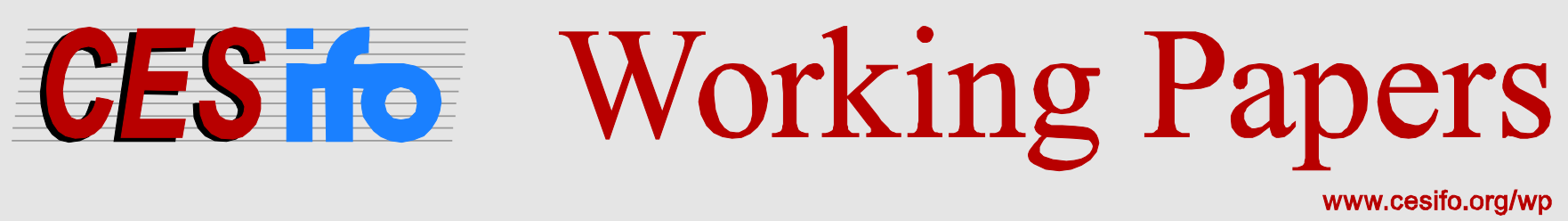

\title{
Income Inequality, Mobility and the Accumulation of Capital
}

\author{
Cecilia García-Peñalosa \\ Stephen J. Turnovsky
}

\author{
CESIFO WORKING PAPER NO. 4559 \\ CATEGORY 6: Fiscal POLICY, MACROECONOMICS AND GROWTH \\ DECEMBER 2013
}

An electronic version of the paper may be downloaded

- from the SSRN website:

- from the RePEc website:

- from the CESifo website:

WwW.SSRN.com

Www.RePEc.org

www.CESifo-group.org/wp

\section{CESifo}




\title{
Income Inequality, Mobility and the Accumulation of Capital
}

\begin{abstract}
We examine the determinants of income mobility and inequality in a Ramsey model with elastic labor supply and heterogeneous wealth and ability (labor endowment). Both agents with lower wealth and with greater ability tend to supply more labor, implying that labor supply decisions may have an equalizing or unequalizing effect depending on the relative importance of the two sources of heterogeneity. Moreover, these decisions are central to the extent of mobility observed in an economy. The relationship between mobility and inequality is complex. For example, a reduction in the interest rate and an increase in the wage rate reduce capital income inequality and allow upward mobility of the ability-rich. However, the increase in the labor supply of high ability agents in response to higher wages raises earnings dispersion and thus has an offsetting effect. As a result, high mobility can be associated with an increase or a decrease in overall income inequality.
\end{abstract}

JEL-Code: D310, O410.

Keywords: inequality, income mobility, endogenous labor supply, transitional dynamics.

\author{
Cecilia García-Peñalosa \\ Aix-Marseille University \\ School of Economics \\ Marseille / France \\ cecilia.garcia-penalosa@univ-amu.fr
}

\author{
Stephen J. Turnovsky \\ Economics Department \\ University of Washington \\ USA - 98195 Seattle WA \\ sturn@u.washington.edu
}

Revised version September 2013

This paper is a revised version of a plenary address presented to the 17th International Conference on Macroeconomic Analysis and International Finance held in Rethymno, Crete 2013. It has also benefited from comments received at workshops on macroeconomic dynamics held in Bolzano, Italy, the 2012 SWIM workshop in Auckland, NZ, and the 2013 APET Conference held in Lisbon, as well as seminar presentations at the Free University of Berlin, GREQAM, and Boğaziçi University, Istanbul. García-Peñalosa acknowledges the support of the French National Research Agency Grant ANR-08-BLAN-0245-01, while Turnovsky's research was supported in part by the Castor and Van Voorhis endowments at the University of Washington. 


\section{Introduction}

Recently, macroeconomists have shown how, under widely adopted assumptions, the basic Ramsey model, which conventionally treats all agents as identical, can in fact accommodate specific sources of heterogeneity, thereby enabling it to address questions pertaining to wealth and income inequality. Most applications are restricted to a single source of heterogeneity, the most common, and arguably the most relevant, being the initial endowments of capital. ${ }^{1}$ But while a single source of heterogeneity can generate inequality, it cannot address issues pertaining to wealth and income mobility, for which the simultaneous introduction of (at least) two independent sources of heterogeneity is required. This was first demonstrated by Caselli and Ventura (2000), who introduced "labor endowments", or ability, as a second source of heterogeneity.

The notion of wealth and income mobility refers to the potential for initially less wealthy, but more skilled, agents over time to overtake wealthier, but less skilled, agents in the distributions of wealth and income. It is an important issue in appreciating the significance of inequality, and for designing policies to address it. Clearly, inequality is a more serious problem in an economy having low mobility so that individuals at the bottom of the distribution are condemned to remain there, while it is less serious if more able people are able to move up the income scale. ${ }^{2}$ Several empirical studies analyze the relationship between mobility and inequality and the potential tradeoffs.

This empirical work on income mobility has traditionally focused on mobility across generations, and the evidence indicates that changes in relative income positions are substantial and affected by a country's policies and institutional environment; see, for example, Checchi, Ichino, and Rustichini (1999), Solon (1999), and Lee and Solon (2009). Much of this work has focused on labor income changes, and in line with such evidence models have been developed where mobility is generated by idiosyncratic labor income shocks; see Castañeda, Díaz-Giménez, and Rios-Rull (1998), Krusell and Smith (1998), and Maliar and Maliar (2003). Recent empirical work has, however, emphasized the importance of the intergenerational transmission of wealth. Aggregate wealth to income ratios seem to have been growing in recent decades and some countries, such as

\footnotetext{
${ }^{1}$ See, for example, Chatterjee (1994), Maliar and Maliar (2001), Caselli and Ventura, and our earlier papers.

${ }^{2}$ See, for example, Roemer (1998) for a discussion of the different concepts on inequality.
} 
France, exhibit an upward trend in inheritances as a share of national income; see Piketty (2011) and Piketty and Zucman (2013). In the light of this evidence, greater effort is needed to develop models that incorporate both the possibility of earnings and wealth mobility.

While Caselli and Ventura (2000) introduce the potential for mobility, they do not address it in depth. They also assume that labor is supplied inelastically, which is a serious limitation, since the adjustment of labor is a crucial determinant of both inequality and mobility. Accordingly, in this paper we adopt the Ramsey framework, employed by Caselli and Ventura (2000), augmented to incorporate endogenous labor supply, to examine the role of the labor supply responses in generating the distributional effects of the two sources of endowments, and how they impact income mobility. ${ }^{3}$

One of the shortcomings of assuming a fixed labor supply is that the relative importance of ability and wealth in an agent's income at any point in time depends only on the endogenous factor prices prevailing at that time. Moreover, although the distribution of total income evolves over time, that of earnings remains constant, determined by the exogenous distribution of ability. Endogenizing labor supply is hence particularly critical in an economy with skill heterogeneity, where agents of varying abilities, receiving differential wages, have different incentives to adjust their respective labor supplies in response to the evolving returns to capital and labor. In this context two effects arise. On the one hand, wealthier agents work less, and this has an important equalizing effect, as we have shown in previous work. ${ }^{4}$ On the other, more skilled agents tend to supply more labor, and this has an offsetting unequalizing effect. Moreover, in contrast to when labor is supplied inelastically, the distribution of earnings differs from that of skills, and will change with the evolution of macroeconomic aggregates, even if the underlying dispersion of abilities is remains constant. As a result, the distributions of both capital and labor incomes evolve endogenously.

Two main results emerge from our analysis. First, labor supply is decreasing in wealth but

\footnotetext{
${ }^{3}$ As we will see below and has been previously shown, representing preferences by a utility function that is homogeneous in consumption and leisure facilitates aggregation as in Gorman (1953), and generates a representativeconsumer characterization of the macroeconomic equilibrium. Without the homogeneity assumption, aggregate behavior and distribution become simultaneously determined and analysis of the transitional dynamics becomes analytically intractable. See, for example, Krusell and Smith (1998).

${ }^{4}$ See García-Peñalosa and Turnovsky $(2007,2011)$ and Turnovsky and García-Peñalosa (2008). There is substantial empirical evidence in support of this negative relationship between wealth and labor supply. Holtz-Eakin, Joulfaian, and Rosen (1993) provided evidence to suggest that large inheritances decrease labor participation. Cheng and French (2000) and Coronado and Perozek (2003) for the US and Algan, Chéron, Hairault, and Langot (2003) for France find significant wealth effects on the extensive margin of labor supply.
} 
increasing in ability. As a result, there is a tension between the equalizing forces stemming from the former effect, and the unequalizing ones resulting from the latter, determining whether the elasticity of labor supply boosts or dampens inequality. Second, the elasticity of labor plays a key role in determining the degree of mobility. To understand this, consider a transition towards the steady state in which wages are growing and high ability individuals are upwardly mobile. Their capacity to catch up depends on the elasticity of labor: since labor supply responses increase (decrease) the earnings of the ability-rich (capital-rich) they facilitate income catch-up. As a result, the more elastic is labor, the stronger these effects will be, and the easier mobility becomes.

Our analysis also shows that enhanced mobility need not imply less income inequality, the reason for this again being the response of the labor supply. For example, a shock that results in a large increase in wages together with a large reduction in the interest rate would give rise to substantial mobility. Because ability is unequally distributed, the increase in the wage would imply an increase in earnings inequality, thus offsetting the equalizing effect of a reduction in the interest rate. If the increase in earnings dispersion is sufficiently large, the shock may result in both high mobility and an increase in income inequality.

Following this introduction, Section 2 describes the economy and Section 3 derives the macroeconomic equilibrium and characterizes the dynamics of relative wealth and relative income. Section 4 defines income mobility, derives its dynamics, and examines how it relates to income inequality. The effects of changes in fundamentals and tax rates on the long-run distributions of wealth and income are then illustrated in Section 5 with a number of numerical examples. Section 6 concludes, while insofar as possible technical details are relegated to the Appendix.

\section{The analytical framework}

\subsection{Consumers}

The economy is populated by $N$ individuals, each indexed by $i$. There are two sources of heterogeneity: agents' relative skill levels, denoted by $a_{i}$, and their initial endowments of capital, $K_{i, 0}$. By defining $a_{i}$ in terms of relative skills, the average economy-wide skill level is simply $\sum_{i} a_{i} / N=1$. The heterogeneity of relative skills across agents is described by its (constant) 
standard deviation, $\sigma_{a}$. Relative capital (wealth) is defined by $k_{i}(t) \equiv K_{i}(t) / K(t)$, where $K(t)$ is the average economy-wide capital stock at time $t$. At any point of time the relative capital stock has mean 1, while its dispersion across agents is given by the standard deviation, $\sigma_{k}(t)$, with the initial (given) dispersion being $\sigma_{k, 0}$. The correlation between initial capital endowments and skills is denoted by $\chi$, and may be ${ }_{<}^{>} 0 .^{5}$

Each individual is endowed with a unit of time that can be allocated either to leisure, $l_{i}$, or to supplying labor, $1-l_{i} \equiv L_{i}$. The agent maximizes lifetime utility, assumed to be an isoelastic function of consumption and leisure plus an additively separable function of government expenditure

$$
\max \int_{0}^{\infty}\left[\frac{1}{\gamma}\left(C_{i}(t) l_{i}(t)^{\eta}\right)^{\gamma}+v(G(t))\right] e^{-\beta t} d t, \text { with } \quad-\infty<\gamma<1, \eta \geq 0, \gamma \eta<1, \gamma(1+\eta)<1
$$

where $G(t)$ is per capita government expenditure and $v^{\prime}>0 .^{6}$ The intertemporal elasticity of substitution is given by $1 /(1-\gamma)$ and the parameter $\eta$ represents the elasticity of leisure in utility.

This maximization is subject to the agent's capital accumulation constraint

$$
\dot{K}_{i}(t)=\left[\left(1-\tau_{k}\right) r(t)-\delta\right] K_{i}(t)+\left(1-\tau_{w}\right) w_{i}(t)\left(1-l_{i}(t)\right)-C_{i}(t)+T_{i}
$$

where $r(t)$ is the return to capital, $w_{i}(t)$ the wage received by the individual, $\delta$ the capital depreciation rate, $\tau_{k}$ and $\tau_{w}$ are the tax rates on capital income and labor income, respectively, and $T_{i}$ are the transfers received by agent $i$.

\subsection{Technology and factor payments}

A representative firm produces aggregate output using a neoclassical production function

$$
Y=F(K, L) \quad F_{L}>0, F_{K}>0, F_{L L}<0, F_{K K}<0, F_{L K}>0
$$

where $K, L$ and $Y$ denote respectively the per capita stock of capital, effective labor supply, and per

\footnotetext{
${ }^{5}$ The initial distribution may be of any arbitrary form, the only restriction being that the largest initial wealth endowment is less than the level, $\bar{k}$, that would induce that individual to withdraw entirely from the labor market (i.e. supply zero labor).The value of this upper bound can be obtained from the expressions for labor supply and steady state capital derived below; see footnote 14 .

${ }^{6}$ The assumption of additive separability is made simply for convenience. See García-Peñalosa and Turnovsky (2011) for a discussion of alternative utility functions in the case of one source of heterogeneity.
} 
capita output. Since labor productivity is heterogeneous, the effective labor employed by the firm is $L=1 / N \sum_{i} a_{i} L_{i}$. Firms pay capital and labor according to their marginal physical products, so that $r(t) \equiv r(K, L)=F_{K}(K, L)$ and $w_{i}(K, L)=a_{i} w(K, L)$, where $w(t) \equiv w(K, L)=F_{L}(K, L)$ is the average wage rate and the wage received by agent $i, w_{i}$, reflects his skill level. Thus, the distribution of relative wage rates, $w_{i}(t) / w(t)$, is unchanging and simply reflects the given distribution of skill levels across agents.

\subsection{Government}

We assume that the government sets its expenditure and transfers as fractions of per capita output, in accordance with $G=g Y(t), T=\tau Y(t)$, so that $g$ and $\tau$ become the policy variables together with the tax rates. We also assume that it maintains a balanced budget expressed as

$$
\tau_{k} r K+\tau_{w} w L=G+T=(g+\tau) F(K, L)
$$

This means that, if $\tau_{w}, \tau_{k}$, and $g$ are fixed, as we shall assume, then along the transitional path, as economic activity and the tax/expenditure base is changing, the rate of lump-sum transfers must be continuously adjusted to maintain budget balance. To abstract from any direct distribution effects arising from lump-sum transfers (which are arbitrary), we shall set $T=0$ in steady state.

\subsection{The macroeconomic equilibrium}

Summing $K_{i}, l_{i}$ over all agents, equilibrium in the capital and labor markets is described by

$$
\begin{aligned}
& K(t)=\frac{1}{N} \sum_{i} K_{i}(t) \\
& L(t)=(1-\Omega l(t)) \quad \text { where } \Omega \equiv \frac{1}{N} \sum_{i} a_{i} \rho_{i}
\end{aligned}
$$

and $l_{i}=\rho_{i} l$. The term $\rho_{i}$ is the relative leisure of agent $i$, and which is constant over time, and, $\sum_{i} \rho_{i} / N=1 .{ }^{7}$ Assuming that the effective labor supply is positive, $L(t)>0,(5 \mathrm{~b})$ implies $1>\Omega l(t)$, where $\Omega l(t)$ is effective leisure. Thus $\Omega$ measures the labor lost through leisure, with the losses

\footnotetext{
${ }^{7}$ This follows from the fact that that leisure is growing at the same rate for all agents, as shown in the expanded version of this paper, García-Peñalosa and Turnovsky (2012).
} 
incurred by each individual being weighted by their level of ability. Moreover, because ability is given and $\rho_{i}$ is constant during the transition to a steady state, $\Omega$ does not change over time, implying that the dynamics of effective leisure, $\Omega l(t)$, will reflect the dynamics of $l(t)$.

The derivation of the macroeconomic equilibrium follows Turnovsky and García-Peñalosa (2008) and is briefly summarized in the expanded version of this paper. There we show that the dynamic equations governing aggregate behavior are just those of the standard Ramsey model with endogenous labor supply, implying that the evolution of the aggregate capital stock and labor supply are independent of any distributional characteristics. Assuming that the economy is stable, aggregate quantities converge to a steady state characterized by a constant average per capita capital stock, labor supply, and effective leisure time, denoted by $\tilde{K}, \tilde{L}$ and $\Omega \tilde{l}$, respectively, and given by

$$
\begin{aligned}
& \left(1-\tau_{k}\right) F_{K}(\tilde{K}, \tilde{L})=\beta+\delta \\
& (1-g) F(\tilde{K}, \tilde{L})-\delta \tilde{K}=\left(1-\tau_{w}\right) F_{L}(\tilde{K}, \tilde{L}) \frac{(1-\tilde{L})}{\eta} \\
& \tilde{L}+\Omega \tilde{l}=1
\end{aligned}
$$

The first two equations jointly determine per capita steady-state values of capital and labor, with $\Omega \tilde{l}$ being determined by (6c). In fact, (6c) implies only effective, but not average, leisure, which requires knowledge of $\Omega$, and hence of the distribution of ability across agents.

Rewriting equation (6b), we can show that if the share of private consumption expenditure, $(1-g)-\delta(\tilde{K} / \tilde{F})$, exceeds the after-tax share of labor income, $\left(1-\tau_{w}\right)\left(\tilde{F}_{L} \tilde{L} / \tilde{F}\right)$, then (6b) imposes the restriction $1 /(1+\eta)>\widetilde{L}>0 .^{8}$ As we will see below, this condition plays a critical role in characterizing the dynamics of the wealth distribution. It imposes an upper (lower) bound on the steady-state time allocation to labor supply (leisure) that is consistent with a sustainable equilibrium.

Lastly, it can be shown that the (locally) stable path for $K(t)$ and $L(t)$ in the neighborhood of steady state can be expressed as $K(t)=\tilde{K}+\left(K_{0}-\tilde{K}\right) e^{\mu t}$ and $L(t)=\widetilde{L}+\left(\mu-b_{11}\right) / b_{12}(K(t)-\widetilde{K})$, where $\mu<0$ is the stable eigenvalue and $b_{12}>0$.As we will see below, the evolution of average

\footnotetext{
${ }^{\mathbf{8}}$ This restriction, which we impose, and can be expressed equivalently as $1>\Omega \tilde{l}>\eta /(1+\eta)$ is relatively weak, and is satisfied for plausible choices of parameters.
} 
labor supply over time is an essential determinant of the time path of both inequality and mobility. The stable saddle path is negatively sloped if and only if $\mu<b_{11}$, which elsewhere we have argued is the more plausible case; see García-Peñalosa and Turnovsky (2012) for further discussion. ${ }^{\mathbf{9}}$

In addition, for expositional convenience we shall focus on situations in which the economy is subject to an expansionary structural shock that results in an increase in the steady-state average per capita capital stock relative to its initial level $\left(K_{0}<\tilde{K}\right)$. This will lead to an initial positive jump in labor supply, such that $L(0)>\tilde{L}$, so that thereafter, labor supply will decrease monotonically during the transition; an analogous relationship applies if $K_{0}>\tilde{K}$.

\section{The dynamics of relative wealth and income}

\subsection{The relative labor supply}

To derive the dynamics of individual $i$ 's relative capital stock, $k_{i}(t) \equiv K_{i}(t) / K(t)$, we follow Turnovsky and García-Peñalosa (2008), using the individual's budget constraint (2) together with the aggregate constraint. Assuming that $T_{i} / K_{i}=T / K$ this leads to ${ }^{\mathbf{1 0}}$

$$
\dot{k}_{i}(t)=\frac{w(K, L)\left(1-\tau_{w}\right)}{K}\left[\left(a_{i}-a_{i} \rho_{i} l \frac{1+\eta}{\eta}\right)-\left(1-\Omega l \frac{1+\eta}{\eta}\right) k_{i}(t)\right]
$$

where initial relative capital $k_{i, 0}$ is given from the initial endowment and the aggregate magnitudes $K$ and $\Omega l=1-L$ change over time.

Equation (7) together with the constancy of $\rho_{i}$ implies the following relationship between agent $i$ 's allocation of time to labor, his steady-state relative capital, $\tilde{k}_{i}$, and his (given) ability:

$$
L_{i}(t)-L(t)=\frac{l(t)}{\tilde{l}}\left(\tilde{L}-\frac{1}{1+\eta}\right)\left(\frac{\tilde{k}_{i}}{a_{i}}-1\right) \quad \text { for each } i
$$

This equation captures one of the critical elements determining the evolution of the distributions of

\footnotetext{
${ }^{9}$ In the Ramsey model with inelastic labor supply the stable saddle path is a positive relationship between consumption and capital. Since leisure and consumption are Edgeworth complements, with elastic labor supply this implies a positive relationship between leisure and capital, or equivalently a negative relationship between labor and capital.

${ }^{10}$ Since $T=0$ in steady state we simply assume that during the transition $T_{i}(t) / T(t)=K_{i}(t) / K(t)$. The role of transfers is then only to ensure a balanced budget during the transition. For more details see Turnovsky and García-Peñalosa (2008). An alternative lump-sum transfer rule $T_{i}=T$, yields only minor differences in results from those reported here.
} 
wealth and income and explains why the dynamics of the aggregate quantities are unaffected by distributional aspects. The reason is simply that each agent's labor supply is a linear function of the ratio of his relative capital to ability, with this sensitivity being common to all agents and depending upon the aggregate economy-wide labor/leisure allocation. Moreover, equation (8) implies that the greater this ratio, the more leisure the agent consumes and the less labor he supplies. This has two effects, an equalizing effect that partly offsets the impact of wealth inequality on the distribution of income and an unequalizing effect that magnifies the effect of differences in ability. When capital is more unequally distributed than labor endowments, the former effect will dominate and the impact of labor supply responses will be to reduce income inequality as compared to a situation in which the labor supply is inelastic and common to all agents.

\subsection{The dynamics of relative wealth, earnings and income}

We are interested in the dynamics of three quantities: (i) an agent's relative capital, $k_{i}(t)$, (ii) his relative income derived from labor (or "earnings") defined as $y_{i}^{e}(t) \equiv a_{i} w(t) L_{i}(t) /(w(t) L(t))$, and (iii) his relative total income, $y_{i}(t)=s_{K}(t) k_{i}(t)+s_{L}(t) a_{i} L_{i}(t) / L(t)$, where $s_{K} \equiv F_{K} K / F, s_{L}=1-s_{K}$

denote the shares of capital and labor income. ${ }^{11}$ In the expanded version of this paper we show that the dynamics of these three quantities are respectively:

$$
\begin{gathered}
k_{i}(t)=\frac{1+\theta(t)}{1+\theta(0)} k_{i, 0}+\frac{\theta(0)-\theta(t)}{1+\theta(0)} a_{i} \\
y_{i}^{e}(t)=a_{i}+\frac{l(t)}{\tilde{l}}\left((1+\eta)^{-1}-\tilde{L}\right) \frac{1}{1+\theta(t)} \frac{a_{i}-k_{i}(t)}{L(t)} \\
y_{i}(t)=\varphi(t) k_{i}(t)+(1-\varphi(t)) a_{i}=\varphi(t)\left[\frac{1+\theta(t)}{1+\theta(0)}\right] k_{i, 0}+\left[1-\varphi(t) \frac{1+\theta(t)}{1+\theta(0)}\right] a_{i}
\end{gathered}
$$

where

$$
\theta(0) \equiv \frac{F_{L}(\tilde{K}, \tilde{L})\left(1-\tau_{w}\right) / \tilde{K}}{\left(F_{L}(\tilde{K}, \tilde{L})\left(1-\tau_{w}\right) / \tilde{K}\right)\left(1+\eta^{-1}\right)\left((1+\eta)^{-1}-\tilde{L}\right)-\mu}\left(\frac{L(0)-\tilde{L}}{1-\tilde{L}}\right)
$$

\footnotetext{
${ }^{11}$ With distortionary taxes, before- and after-tax incomes will generally not coincide. We consider here the evolution of before-tax income, while a discussion of after-tax income can be found in the working paper version of this article.
} 


$$
\begin{aligned}
& \theta(t)=\theta(0) e^{\mu t} \\
& \varphi(t) \equiv\left[s_{K}(t)+s_{L}(t) \frac{l(t)}{\tilde{l} L(t)}\left(\tilde{L}-(1+\eta)^{-1}\right) \frac{1}{1+\theta(t)}\right]
\end{aligned}
$$

Equations (9) and (11) imply that, as shown by Maliar, Maliar, and Mora (2005), both current wealth and current income are weighted averages of the individual's endowments of initial wealth and ability, with the weights changing with factor prices. In an expanding economy, $L(0)>\tilde{L}$, which from (13) and (14) implies that over time the relative weight shifts from the endowment of capital toward skills.

Note that the weight on capital will be less than the share of capital $\left(\varphi(t)<s_{K}(t)\right)$, while that on ability will exceed the labor share. This is because of the opposite signs of labor supply responses to wealth and ability [see (8)]. ${ }^{12}$ In contrast, with inelastic labor supply as in Caselli and Ventura (2000) and Maliar, Maliar, and Mora (2005), the weights of current wealth and ability in income always equal the aggregate capital and labor shares.

Moreover, with a constant supply of labor, relative wealth and income change only slowly as the capital stock converges to its new steady state. With endogenous labor, equation (14) implies that, following a shock, $\varphi(t)$ will jump as a result of the jump in labor induced by the shock. Relative income may hence change substantially on impact in response to the new factor prices, even if relative wealth changes only slowly during the transition to a new steady state. ${ }^{13}$

Consider now equation (10) driving the dynamics of earnings. This expression highlights how, whether an agent's relative earnings exceed or are less than his relative ability, depends on his comparative position in the wealth and ability distributions. If he is more endowed (relatively) in ability, his labor supply will be above average and this will tend to raise his relative earnings. The opposite applies if he is more endowed with capital. The dispersion of earnings will then depend on both the elasticity of labor and the relative dispersions of ability and capital. If the labor supply were inelastic, relative earnings would be unchanged over time and equal to relative ability, i.e. $y_{i}^{e}(t)=a_{i}$.

\footnotetext{
${ }^{12}$ Although we cannot rule out $\varphi(t)<0$ at some point along the transitional path, in steady state $0<\tilde{\varphi}<\tilde{s}_{K}$ if and only if, $1 /(1+\eta)>\tilde{L}>\tilde{s}_{L} /(1+\eta)$ a condition that is met for the benchmark calibrations below.

${ }^{13}$ More details on the dynamic response of relative income can be found in Turnovsky and García-Peñalosa (2008) and García-Peñalosa and Turnovsky (2011). The qualitative effects are the same with or without ability differences.
} 
An elastic labor supply implies that agents' responses will magnify or reduce this difference depending on the distributions of the two endowments and their correlation.

\subsection{Wealth and income inequality}

Because of the linearity of the expressions for relative wealth, (9), we can immediately transform these expressions into corresponding measures of aggregate wealth inequality. There are several such measures, each having its advantages and drawbacks, while yielding similar qualitative implications. One natural inequality measure is in terms of relative deviations, $\sigma_{k}-$ essentially the coefficient of variation $(\mathrm{CV})$ - which is dimensionally equivalent to the widely used Gini coefficient. But with more than one source of inequality, as we have here, it may be useful to decompose it into its underlying components, for which neither the CV nor Gini are convenient. In this case, the squared coefficient of variation $(\mathrm{SCV}), \sigma_{k}^{2}$, is a natural member of the class of decomposable inequality measures identified by Bourguignon (1979) and hence is the measure that we shall employ.

Thus, recalling (9) and the definitions of $\sigma_{k, 0}$ (initial distribution of capital) and $\sigma_{a}$ (distribution of skills), we can write $\sigma_{k}^{2}(t)$ as

$$
\sigma_{k}^{2}(t)=\frac{1}{[1+\theta(0)]^{2}}\left([1+\theta(t)]^{2} \sigma_{k, 0}^{2}+[\theta(0)-\theta(t)]^{2} \sigma_{a}^{2}+2(1+\theta(t))[\theta(0)-\theta(t)] \sigma_{k, 0} \sigma_{a} \chi\right)
$$

where $\chi$ is the correlation between capital endowments and skills. Letting $t \rightarrow \infty$ in (15) yields

$$
\tilde{\sigma}_{k}^{2}=\frac{1}{[1+\theta(0)]^{2}}\left(\sigma_{k, 0}^{2}+\theta^{2}(0) \sigma_{a}^{2}+2 \theta(0) \sigma_{k, 0} \sigma_{a} \chi\right)
$$

From these expressions we see that in an economy that is accumulating capital as a result of an expansionary external shock, wealth inequality may increase or decrease, depending upon the relative dispersions of the initial endowments of capital and skills and their correlation. Note also that wealth inequality can emerge from differences in skill endowments alone, i.e. if $\sigma_{k, 0}=0$.

Those with higher ability will accumulate capital faster, and the effect of relative skill endowments depends crucially upon $\theta(0)$, which in turn depends upon labor supply reactions.

Analogously, we can express income inequality in terms of its SCV. Using equation (14) 
and defining $\phi(t) \equiv \varphi(t)(1+\theta(t)) /(1+\theta(0))$, the SCV of (pre-tax) income can be written as

$$
\sigma_{y}^{2}(t)=\varphi(t)^{2} \sigma_{k, 0}^{2}+(1-\varphi(t))^{2} \sigma_{a}^{2}+2 \varphi(t)(1-\varphi(t)) \sigma_{k, 0} \sigma_{a} \chi
$$

which depends on initial endowments and the evolution of factor prices.

\section{Wealth and income mobility}

We can now consider the possibility of mobility. To understand the source of the potential for agents to change their relative wealth positions, we write the difference between an agent's longrun relative capital and the mean as

$$
\tilde{k}_{i}-1=\frac{1}{1+\theta(0)}\left(k_{i, 0}-1\right)+\left(\frac{\theta(0)}{1+\theta(0)}\right)\left(a_{i}-1\right)=\frac{1}{1+\theta(t)}\left[\left(k_{i}(t)-1\right)+\theta(t)\left(a_{i}-1\right)\right]
$$

From these expressions we see that if an agent begins with above-average capital (i.e. $k_{i, 0}>1$ ), but is endowed with below-average skills (i.e. $a_{i}<1$ ), he may end up with below-average capital. This is because there are two offsetting forces driving the accumulation of capital. ${ }^{14}$ On the one hand, individuals with large initial wealth accumulate capital more slowly (during an expansion), which tends to deteriorate their relative position. On the other hand, those having more ability have higher incomes, ceteris paribus, and hence accumulate more capital, which tends to improve their relative position. As a result, the potential for wealth mobility exists.

Compare now two individuals $i, j$, and express their wealth gap at time $t$ as

$$
k_{i}(t)-k_{j}(t)=\frac{1+\theta(t)}{1+\theta(0)} \Delta k+\frac{\theta(0)-\theta(t)}{1+\theta(0)} \Delta a
$$

where $\Delta a \equiv a_{i}-a_{j}$ and $\Delta k \equiv k_{i, 0}-k_{j, 0}$. This expression indicates that there are two offsetting forces influencing this gap, the differences in initial capital and the differences in ability. In a growing economy, $\theta(0)>\theta(t), \dot{\theta}(t)<0$, implying that the term multiplying the capital gap is less than one and declining over time. As in Turnovsky and García-Peñalosa (2008), when the economy is

\footnotetext{
${ }^{14}$ This expression can be used, together with the individual's budget constraint, to show that for all agents to supply a strictly positive amount of labor in the steady state the initial distribution of capital must be such that an agent with ability $a_{i}$ has an endowment below $\bar{k} \equiv a_{i}\left[\left(1+\theta_{0}\right) s_{L} /\left(\eta L s_{K}\right)-\theta_{0}\right]$.
} 
accumulating capital, savings behavior and the dynamics of factor returns reduce capital inequality. At the same time, the coefficient on the skill gap is positive and growing over time, and this tends to increase wealth differentials. This is becausethe more able agents have higher labor incomes and will accumulate capital faster than those having lesser ability.

From (19) and (14), the initially less wealthy individual, agent $j$ say, will catch up to the richer one, agent $i$, at time $\hat{t}$, determined by

$$
\hat{t}=\frac{1}{\mu} \ln \left(\frac{\left(a_{i}-a_{j}\right)+\left(k_{i, 0}-k_{j, 0}\right) / \theta(0)}{\left(a_{i}-a_{j}\right)-\left(k_{i, 0}-k_{j, 0}\right)}\right)
$$

Clearly, catch-up will occur if and only if $\hat{t}>0$, enabling us to state:

Proposition 1: In an economy that is accumulating capital $[\theta(0)>0]$,

(i) if individual $j$ is initially endowed with less wealth than is individual $i$, the poorer agent will catch up in wealth if and only if $-\Delta a \cdot \theta(0)>\Delta k$;

(ii) if individual $j$ is initially endowed with both less wealth and less ability than individual $i$, the poorer agent will never catch up.

\section{Proof: See Appendix.}

This proposition indicates that the poorer agent will catch up in wealth if and only if he has sufficiently superior ability. It captures the conflict between the two forces discussed above: both more wealth and greater ability imply, other things equal, higher income and more savings. An initially less wealthy individual can catch up only if he is sufficiently able, so that he accumulates faster than does the wealthier, but less able, individual. If in addition to having less capital he also has less ability, he will never catch up.

Compare now two individuals $i, j$, in an initial steady state, where $i$ has greater initial income, i.e. $y_{i, 0}>y_{j, 0}$. In the initial equilibrium $y_{i, 0}-y_{j, 0}=\tilde{\varphi}_{0}\left(k_{i, 0}-k_{j, 0}\right)+\left(1-\tilde{\varphi}_{0}\right)\left(a_{i}-a_{j}\right)>0$, where $\tilde{\varphi}_{0} \equiv 1-\left(\tilde{s}_{L, 0} / \tilde{L}_{0}\right)(1 /(1+\eta))$. Clearly, $i$ may have higher initial income either because he has more ability than $j$, because he is initially wealthier, or both. The potential for income mobility is complex since any shock will generate an initial jump in labor and hence in factor prices, as well as a smooth 
evolution of the latter during the subsequent transition path. There are thus two ways in which a shock can result in income catch-up. If $y_{i}(0)<y_{j}(0)$, then following the shock agent $j$ immediately overtakes agent $i$ in income. Alternatively, if $y_{i}(0)>y_{j}(0)$ and $\tilde{y}_{i}<\tilde{y}_{j}$, agent $j$ overtakes agent $i$ along the transition. Since instantaneous catch-up is unlikely, we shall focus attention on the more plausible case where it occurs along the transitional path. The following proposition specifies the circumstance under which such mobility is possible:

Proposition 2: Individual $i$ may initially be richer than individual $j$ because of higher initial wealth, higher ability, or both. If that is the case, then

(i) if $i$ has a larger endowment both of ability and wealth, $j$ cannot catch up to $i$ 's income level;

(ii) if individual $j$ is initially endowed with less wealth than is individual $i$, the poorer agent will catch up in income along the transitional path if and only if

$$
\frac{\tilde{\varphi}}{1+\theta(0)-\tilde{\varphi}}<-\frac{\Delta a}{\Delta k}<\frac{\varphi(0)}{1-\varphi(0)}
$$

and the economy satisfies $\varphi(0)>\tilde{\varphi} /(1+\theta(0))$;

(iii) if individual $j$ is initially endowed with less skill than is individual $i$, the poorer agent will catch up in income if and only if

$$
\frac{\tilde{\varphi}}{1+\theta(0)-\tilde{\varphi}}>-\frac{\Delta a}{\Delta k}>\frac{\varphi(0)}{1-\varphi(0)}
$$

and the economy satisfies $\varphi(0)<\tilde{\varphi} /(1+\theta(0))$.

\section{Proof: See Appendix.}

Proposition 2 indicates that, as the economy converges to a steady state, income mobility is possible for only one type of agent, either the skill-rich or the capital-rich, but not both. This is because income mobility depends on the behavior of factor prices. If wages are growing fast, then skill-rich agents will be able to catch-up but capital-rich individuals will not, and vice versa. The behavior of factor prices, in turn, depends on both the structure of the aggregate economy and the 
nature of the shock, captured by the sign of $[\varphi(0)-\tilde{\varphi} /(1+\theta(0))]$. For Cobb-Douglas production, in a growing economy $\varphi(0)>\tilde{\varphi} /(1+\theta(0))$ always holds. It is then the skill-rich that may catch up in income. In contrast, in a contracting economy it is the capital-rich for whom this is possible.

Note that equation (21a) has a simple interpretation. The right-hand side inequality is the condition for the wealthy individual to have a higher initial income, and simply requires that agent $j$ does not have a sufficiently high skill endowment, relative to the initial wealth gap. The left-hand side inequality says that, given that $i$ has initially higher income, $j$ can catch-up only if his ability gap is sufficiently high. Similarly, from equation (21b) we can see that the right-hand inequality is the condition for $i$ to be initially richer, and the left-hand inequality asserts that mobility can occur only if, given the initial wealth gap, the ability gap is not too large.

We can now specify measures of wealth and income mobility in the economy.

Definition 1. Let $\Delta \hat{a}$ be the minimum ability gap required for $j$ to catch up to $i$ 's wealth, given their initial wealth gap, $\Delta k$. We then define the extent of wealth mobility, denoted $\omega_{k}$, as $\omega_{k} \equiv-(\Delta \hat{a} / \Delta k)^{-1}$.

Our measure of wealth mobility is the inverse of the minimum ability gap required for catchup. That is, the larger the ability gap required in order to catch up to a given wealth gap, the less is mobility. ${ }^{15}$ Using (19) we obtain

$$
\omega_{k}=\theta(0)=\frac{F_{L}(\tilde{K}, \tilde{L})\left(1-\tau_{w}\right) / \tilde{K}}{\left(F_{L}(\tilde{K}, \tilde{L})\left(1-\tau_{w}\right) / \tilde{K}\right)\left(1+\eta^{-1}\right)\left((1+\eta)^{-1}-\tilde{L}\right)-\mu}\left(\frac{L(0)-\tilde{L}}{1-\tilde{L}}\right)
$$

The degree of wealth mobility depends on both the structural characteristics of the aggregate economy and the specific change generating the initial jump in aggregate labor supply. From (18), we see that a larger weight of ability in an agent's steady-state relative wealth will be associated with greater wealth mobility.

\footnotetext{
${ }^{15}$ While this measure is very natural in our context, it is not the measure of mobility commonly found in the literature. Both sociologists and economists usually examine mobility across successive generations, and define it as the probability that an individual is in an income/wealth class above that of his parents; see Piketty (2000) for a survey. In our model, agents are infinitely-lived which does not allow us to use such a measure.
} 
Definition 2. Let $\Delta \bar{a}$ (alternatively $\Delta \bar{k}$ ) be the minimum ability (wealth) gap required for $j$ to catch-up in income when it is the ability-rich (capital-rich) that may experience income mobility. Whenever the skill-rich can catch-up with the capitalrich, we define the measure of income mobility to be $\omega_{y}^{a} \equiv-(\Delta \bar{a} / \Delta k)^{-1}$; whenever it is the capital-rich that are catching up, we define it to be $\omega_{y}^{k} \equiv-(\Delta \bar{k} / \Delta a)^{-1}$.

We measure the degree of income mobility by the endowment gap required for the poorer agent to be able to catch up to the richer one during the transition, where income mobility depends on which agent is doing the catching up. From the definitions of $\omega_{y}^{a}$ and $\omega_{y}^{k}$ we can write

$$
\begin{aligned}
& \omega_{y}^{a}=\frac{1+\theta(0)-\tilde{\varphi}}{\tilde{\varphi}} \\
& \omega_{y}^{k}=\frac{\tilde{\varphi}}{1+\theta(0)-\tilde{\varphi}}
\end{aligned}
$$

A higher value of $\omega_{y}^{a}$ or $\omega_{y}^{k}$ implies that, for given distributions of initial wealth and skills, a greater fraction of the population will change their relative position along the distribution of income. Considering Proposition 1 in conjunction with Proposition 2 enables us to state:

Proposition 3: In a growing economy if agent $i$ catches up to agent $j$ 's level of wealth he will do so only after he has caught up to agent $j$ 's level of income. It is also possible that he will catch up to his level of income, but not to his level of wealth.

\section{Proof: See Appendix.}

The intuition of Proposition 3 is straightforward. Since agents save a fraction of their income strictly less than one and given that $i$ had a higher initial stock of capital, $j$ will manage to accumulate as much wealth as $i$ only if he has a higher level of income. Hence, he must catch up $i$ 's income level before he can catch-up to his wealth.

Note that our measure of mobility does not capture actual mobility, but rather the potential for wealth or income catch-up in response to a shock to the economy. It is hence unaffected by either the dispersion of endowments or the correlation between them, but is responsive to the nature of the 
shock and to parameter and policy values. Actual mobility - which we do not measure - depends on both our measures of potential mobility $\left(\omega_{k}, \omega_{y}^{a}\right.$ and $\left.\omega_{y}^{k}\right)$ and on the distributional parameters, the two initial distributions $\sigma_{a}$ and $\sigma_{k, 0}$, as well as the correlation between the two endowments $\chi$. This correlation plays an important role in actual mobility, since mobility is impossible if the two endowments are perfectly positively correlated. To see this, note that the endowments would be perfectly correlated if initial ability were proportional to wealth, so that $a_{i, 0}=v k_{i, 0}$ where $v$ is a constant. Then equation (19) implies that $k_{i}(t)-k_{j}(t)=(1+(1-v) \theta(t)+v \theta(0)) \Delta k /(1+\theta(0))$, and if the correlation is positive, i.e. $v>0$, then $k_{i}(t)-k_{j}(t)$ will have the same sign as $k_{i, 0}-k_{j, 0}$ and there will be no wealth mobility. From equation (11) we can see that there will be no income mobility either. Mobility thus requires imperfectly correlated endowments or, if the two are perfectly correlated, that their covariance be sufficiently negative. ${ }^{\mathbf{1 6}}$

The final aspect we consider is the relationship between income inequality and the potential for mobility. Using (20) and (23) we can write the change in income inequality following a shock as

$$
\tilde{\sigma}_{y}^{2}-\widetilde{\sigma}_{y, 0}^{2}=\left(\frac{1}{1+\omega_{y}^{a}}-\widetilde{\varphi}_{0}\right)\left\{\left(\frac{1}{1+\omega_{y}^{a}}+\widetilde{\varphi}_{0}\right)\left[\sigma_{k, 0}^{2}+\sigma_{a}^{2}-2 \sigma_{k, 0} \sigma_{a} \chi\right]-2\left[\sigma_{a}^{2}-2 \sigma_{k, 0} \sigma_{a} \chi\right]\right\}
$$

where $\tilde{\varphi}_{0}$ and $\tilde{\varphi}$ are, respectively, the values of $\varphi(t)$ in the initial and in the new steady states. The overall change in income inequality is the result of the change immediately following the shock and caused by the reaction of factor prices and the labor supply, and the change along the subsequent transitional path to the new steady state. Although it is not possible to sign these changes in general, results can be obtained in the case of Cobb-Douglas production. In this case, if the economy experiences an expansionary external shock that leads to an accumulation of capital and does not cause a long-run decline in employment, income inequality initially increases and then declines unambiguously during the transitional phase whenever $\sigma_{a}=0$, while it initially declines and then increases unambiguously during the transitional phase for $\sigma_{k, 0}=0$.

The interesting implication of this equation is that inequality and mobility need not move together. It is possible for a shock to generate substantial income mobility (i.e. result in a large value

\footnotetext{
${ }^{16}$ To see this, note that if $a_{i, 0}=v k_{i, 0}$, the expression $k_{i}(t)-k_{j}(t)=(1+(1-v) \theta(t)+v \theta(0)) \Delta k /(1+\theta(0))$ will have the opposite sign as $\Delta k$ if the parameter $v$ is sufficiently negative. An equivalent result can be obtained for income.
} 
of $\left.\omega_{y}^{a}\right)$ and yet engender small changes in inequality, which would occur if $\left[1 /\left(1+\omega_{y}^{a}\right)-\tilde{\phi}_{0}\right]$ is close to zero. The intuition for this result is that shocks, by affecting factor prices, change who is at the top of the income distribution. A shock that results in a large increase in wages and a large reduction in the interest rate would give rise to substantial mobility. At the same time, because ability is unequally distributed, the increase in the wage would imply an increase in earnings inequality thus offsetting the equalizing effect that a reduction in the interest rate has. If the increase in earnings dispersion is sufficiently large, high mobility could even be associated with greater income inequality, as captured by the non-monotonicity of the expression in (24) with respect to $\omega_{y}^{a}$.

\section{Numerical Simulations}

To obtain further insights into distributional dynamics we employ numerical simulations, based on the following functional forms and parameter values:

\begin{tabular}{|ll|}
\hline Production function: & $Y=A\left(\alpha K^{-\rho}+(1-\alpha) L^{-\rho}\right)^{-1 / \rho}$ \\
Basic parameters: & $A=1.5, \alpha=0.33$ \\
& $\rho=0$ (elast. of sub. $\varepsilon=1)$ \\
& $\beta=0.04, \gamma=-1.5, \eta=1.75, \delta=0.07$ \\
Fiscal parameters: & $\tau_{k}=\tau_{w}=g=0.22$ \\
Distributions: & low inequality $\sigma_{k 0}^{2}=14, \sigma_{a}^{2}=0.4, \chi=0.33$ \\
& high inequality $\sigma_{k 0}^{2}=28, \sigma_{a}^{2}=0.8, \chi=0.33$ \\
\hline
\end{tabular}

Preferences are summarized by an intertemporal elasticity of substitution $1 /(1-\gamma)=0.4$, rate of time preference of $4 \%$, while the benchmark elasticity of leisure in utility is 1.75 . The production function is CES with distributional parameter $\alpha=0.33$ and with an elasticity of substitution, $\varepsilon=1 /(1+\rho)$, of 1 , while $A=1.5$ scales the level of productivity. The depreciation rate is $7 \%$ per annum. These parameters are all standard and typical of those found in the literature. ${ }^{17}$

The choice of tax rates is less straightforward due to the difficulty of mapping the complexities of the real world tax structure into a simple one-sector growth model. Recently, McDaniel (2007) has computed effective tax rates that can be readily used in macroeconomic

\footnotetext{
${ }^{17}$ For example, the intertemporal elasticity of substitution of 0.4 is well within the range summarized by Guvenen (2006), while the relative weight on leisure in utility is close to the conventional value of the real business cycle literature; see Cooley (1995). The production elasticity $\alpha=0.33$ is also well within the conventional range.
} 
models. Her tax rates indicate substantial fluctuations of tax rates in the US, with the tax rates on capital and labor income varying within the range of $15 \%$ to $30 \%$. In our benchmark numerical examples we set a uniform tax on the two types of income of $22 \%$, even though the two tax rates have tended to differ. This has the advantage that the tax system has no direct distributive effects enabling us to focus on the indirect distributive effects caused by changes in factor rewards. Later we consider how differences between tax rates affect distribution. Finally, we set the government consumption expenditure rate at $g=0.22$, implying that it is entirely financed by the income tax.

We also require estimates of the distributions of ability and initial wealth, together with their correlation. García-Peñalosa and Orgiazzi (2013) decompose overall income inequality in the US into its factor components using the CPS. ${ }^{\mathbf{1 8}}$ Their figures give dispersions (as measured by the SCV) for capital income of 13.17 , for earnings of 0.93 , and for gross income of 0.58 , for the year 1979 . In 2004 these three inequality measures were, respectively, 16.10, 1.34, and 0.82 , capturing the wellknown increase in both income and earnings inequality. Data on the correlation between ability and wealth are unavailable. We choose the initial correlation of the two endowments to be $\chi=0.33$ and set the dispersion of capital to $\sigma_{k 0}^{2}=14$ and that of ability to $\sigma_{a}^{2}=0.4{ }^{19}$ As can be seen in Table 1 , for the benchmark case these parameters will generate dispersions of capital income, earnings and overall income of the same magnitudes as those observed in the data just reported. Because the CPS seems to underestimate inequality in recent years, we also use an alternative set of initial inequality values. We leave the correlation between the two endowments fixed at $\chi=0.33$ and double the dispersion of the other two terms, i.e. $\sigma_{k 0}^{2}=28$ and $\sigma_{a}^{2}=0.8 .^{20}$ The resulting baseline measure of income inequality is $\sigma_{y}^{2}=1.35$, which roughly corresponds to the degree of dispersion reported by Burkhauser et al. (2011) for recent years when they use the uncensored CPS data.

Table 1 reports the benchmark steady-state equilibrium (shown in bold) for the chosen parameters, as well as the long-run responses to changes in technology and preferences. The

\footnotetext{
18 There exist alternative surveys that have been used to look at income inequality, each having advantages and disadvantages, such as the Panel Study on income Dynamics (PSID) and the Survey of Consumer Finances (SCF). The latter has the advantage of oversampling the rich but this oversampling, together with the small sample size (e.g. 4000 observations in 2007 as compared to 77, 000 for the CPS of 2004), results in extremely large measures of inequality; see Díaz-Giménez, Glover and Ríos-Rull (2011).

${ }^{19}$ Robustness analysis with respect to the initial correlation (available upon request) show that income inequality is higher the stronger is the initial correlation yet the patterns we observe below are unaffected by the degree of correlation.

${ }^{20}$ See Burkhauser et al. (2011) on the effect of top-coding of the CPS on measured income dispersion.
} 
benchmark case is reported in the first panel. There we see that the baseline setup, reported on the first line, yields an equilibrium allocation of labor of $27.7 \%$. This figure implies that in steady state the share of income due to capital, given by $\widetilde{\varphi} \equiv 1-\widetilde{s}_{L} /((1+\eta) \widetilde{L})$, is $13 \%$ and $87 \%$ of income is due to skills, roughly consistent with the evidence on factor decompositions of household income. ${ }^{21}$ The dispersion of earnings is 1.422 and that of income 0.676 in the case of low initial inequality, and twice as large for the high inequality case.

The first line of the second panel indicates that with a higher elasticity of substitution in production $(\varepsilon=1.15$ ) the labor supply is lower than in the benchmark case, 0.256 , which results in a greater degree of income inequality since, as we have seen, a lower labor supply results in greater dispersion of working hours and hence of earnings; see equation (10). For the same distributions of ability and initial wealth, we find a dispersion of earnings of 2.534 (respectively 4.707 for the high inequality case) and of income of 0.779 (respectively 1.559). The former is 65 percent higher than in the benchmark, but the increase in income inequality is much smaller due to the positive correlation between leisure and wealth. The level of earnings inequality is implausibly large, the reason for this is that earnings inequality is very sensitive to $\varepsilon$ and that we have chosen the distribution of ability to match the data for low values of $\varepsilon$.

The third panel reports the case of inelastic labor $(\eta=0)$. The dispersion of earnings is now much smaller and equal to that of ability as a result of the absence of labor supply responses. Recall that those endowed with higher ability tend to work more, thus making earnings more dispersed than ability. Without this impact of ability on working time earnings inequality is now lower. In contrast, income inequality is greater than in the benchmark case, assuming a value of 2.049 (4.099) in the low (high) inequality case. The reason for this is the equalizing effect of labor supply reactions to wealth differences. As we have seen, richer agents tend to work less, which reduces, other things constant, their earnings and hence their income. As a result, income inequality is lower than earnings inequality. With a fixed labor supply, the opposite occurs: because the capital-rich supply as much labor as the capital-poor, income inequality is much larger than earnings inequality.

\footnotetext{
${ }^{21}$ The fact that the share of capital in individual incomes is below the aggregate one is well documented. See, for example, Jenkins (1995) and García-Peñalosa and Orgiazzi (2013).
} 
We now consider some examples of shocks and how they affect distribution and mobility. We begin by examining the impact of a productivity increase, and then consider fiscal changes. ${ }^{22}$

\subsection{Increase in the level of technology}

Consider a technological shock, parameterized as an increase in productivity $A$ from 1.5 to 2 . We focus initially on the case of elastically supplied labor, reported in the first two panels, where as noted previously, the transitional adjustment of $\tilde{L}-L(0)$ is a critical determinant of the response of wealth inequality. Hence, both the initial response and the steady-state value of labor are reported. The last two columns of all three panels report our measures of mobility following a shock.

In all cases, steady-state capital and output increase. With elastic labor supply, its long-run supply depends upon whether $\varepsilon \geq 1$. In both cases reported, labor supply declines during the transition, following an initial positive jump for the Cobb-Douglas function but a drop for $\varepsilon=1.15$. With the dispersion of wealth endowments dominating that of ability, the transitional adjustment of labor supply leads to a long-run, gradual and monotonic reduction in wealth inequality, consistent with (21). With elastic labor, we see from the first two panels that the changes in the distribution of wealth that occur during the transition are moderate, with the eventual reduction of wealth inequality ranging from $1.28 \%$ to $3.03 \%{ }^{23}$ Because of the moderate changes in wealth accumulation that occur during the transition, wealth mobility is extremely low. Recalling our definition of wealth mobility, $\omega_{k} \equiv-\Delta k / \Delta \hat{a}$, the figure of 0.016 for the Cobb-Douglas case implies that for agent $j$ (the more able individual) to catch up with the wealth of agent $i$ (the initially wealthier agent) their gap in wealth must be less than 0.016 of their ability gap. In other words, the ability gap of $j$ with respect to $i$ has to be at least 62 times as large as their initial wealth gap!

In contrast to wealth inequality, earnings and income inequality are highly sensitive to the production parameters. For the Cobb-Douglas case, both earnings and income inequality decline following the shock, while for a high elasticity of substitution in production they increase. The

\footnotetext{
${ }^{22}$ Formal expressions describing the responses of the aggregates can be found in García-Peñalosa and Turnovsky (2012).

${ }^{23}$ The fact that most of the adjustment in labor supply occurs on impact is characteristic of this class of model. It reflects the fact that there is no cost to adjusting labor supply. Note also that both the proportional change in inequality and the degree of mobility are unaffected by the initial distributions or wealth and ability, the reason being that both depend on the transitional dynamics of aggregate magnitude which in turn are independent of distribution.
} 
reason for this is the labor supply. With a higher elasticity the reduction in the labor supply results in a sharp increase in wages and thus in earnings inequality which more than offsets the falling wealth inequality, as a result income inequality increases. The last two columns report the mobility measures. Interestingly, our mobility measures are of similar magnitude in the two cases, with mobility being very low for wealth and substantial for ability. In our benchmark case, the ability gap of $j$ with respect to $i$ need be only around $13 \%$ of their initial wealth gap for $j$ to catch-up in income.

The case of inelastic labor supply portrays a very different pattern. First, there is a major difference in the reduction in wealth inequality, which is now over $30 \%$. As we have argued, with elastic labor a major part of the adjustment to the shock takes place through the initial jump in hours, and the transition to the new steady state is hence much faster, resulting in only a small reduction in wealth inequality. The slower transition in the case of inelastic labor implies a major change in the distribution of wealth. Second, earning inequality is unaffected by the shock and hence the evolution of income inequality basically mimics that of wealth. Third, mobility patterns are radically altered. Wealth mobility is high, with the value of $\omega_{k}=0.225$ implying that the ability gap has to be 4.4 times that of capital endowments for catch-up to occur. Income mobility, on the contrary, is lower than in the other two cases. The intuition can be obtained from equation (20'). Mobility is driven by heterogeneity in ability and reinforced by the fact that more able agents also supply more labor. A high elasticity of labor implies a strong labor supply response thus reinforcing the direct effect of ability and making it easier to catch up in income.

Comparing the three panels we derive two main conclusions. First, a similar degree of mobility can be compatible with a reduction in income inequality ( $\varepsilon=1$ and $\eta=1.75$ ) as well as with an increase in inequality $(\varepsilon=1.15$ and $\eta=1.75$ ). Second, the elasticity of labor supply plays a key role in both the degree of mobility and inequality. With fixed labor, inequality changes are much larger, both because of the absence of a change in labor on impact, but also because the equalizing effect that a lower labor supply by the capital-rich has. Mobility presents very different patterns across the two cases. With inelastic labor, wealth mobility is larger and income mobility lower than with elastic labor, the reason being the opposite effects that wealth and ability have on labor supply. 


\subsection{Tax changes and mobility}

The effects of fiscal changes are reported in Table 2, with the two panels corresponding to the benchmark case and that of inelastic labor, respectively. As a first example of the distributional dynamics arising from a change in the fiscal structure, we consider the effect of a balanced reduction in the (common) tax and expenditure rates from $22 \%$ to $17 \%$. The aggregate responses are qualitatively similar to those resulting from an increase in the level of technology.

In the benchmark case the change in wealth, earnings, and income inequality are much milder than those in response to a productivity change; see also García-Peñalosa and Turnovsky (2011). But despite the much smaller changes in inequality, the degree of income mobility is about the same as that generated by a productivity change. This is the result of the direct impact of tax changes on income and labor supply, which is absent in the case of a productivity shock. The consequence of this is that although the reduction in taxes has a small impact on income inequality, those at the top of the income distribution are more likely to be ability-rich than they were before the tax reduction. As in the previous subsection, with a fixed labor supply, income inequality changes are larger and driven by the reduction in wealth inequality, while income mobility is substantially smaller because of the absence of a labor supply response by high ability agents.

Our second exercise is to consider the effects of changing the tax structure to finance a given rate of expenditure, $g .{ }^{24}$ These effects are summarized in the third and fourth lines of the panels in Table 2. We consider two initially identical economies with uniform tax rates, $\tau_{w}=\tau_{k}=g=0,22$, and suppose that they shift their respective tax burdens in opposite directions: one reduces the tax on capital income by 5 percentage points, from $22 \%$ to $17 \%$, offsetting this with an appropriate increase in the tax on labor income; the other reduces the labor income tax by the same magnitude and compensates this by a higher capital income tax. Since the share of labor exceeds that of capital, in the first case the required increase in the labor tax is mild (up to 24.5\%), while in the second case capital income taxes increase sharply (up to $32 \%$ ).

\footnotetext{
${ }^{24}$ Tax structures, and not just tax rates, differ substantially across countries, as documented by McDaniel (2007). Her results indicate that a key feature of the US economy is $\tau_{k}>\tau_{w}$ a characteristic that holds uniformly since 1953. For example, average values of these tax rates for the decade 1991-2000 were $\tau_{k}=0.276$ and $\tau_{w}=0.224$ In contrast, European economies have tended to have a higher effective tax rate of labor than on capital.
} 
The aggregate effects of such compensated tax changes have been extensively studied by García-Peñalosa and Turnovsky (2012). There we see that substituting a tax on labor income for a tax on capital income will reduce long-run employment, while increasing the long-run capital stock, and output (and consumption). The opposite occurs when the capital tax substitutes for a labor tax.

The distributional responses are substantial, certainly much larger than the responses to an increase in the common income tax rate, the reason being that they elicit sharp labor supply responses. $^{25}$ Several general results emerge. First, wealth responses are mild, and wealth mobility requires phenomenally large ability gaps. Second, wealth and earnings inequality move in opposite directions. This is the result of the opposite effects of tax changes on capital and labor. For example, the reduction in the tax on capital income increases the steady-state capital stock and during the transition wealth inequality becomes less dispersed. At the same time, the tax change reduces the labor supply, increasing the dispersion of earnings. These two forces have opposite effects on the distribution of income. Third, the economy with the low capital income tax exhibits much lower income inequality than that with the high capital income tax. Although it seems puzzling that lower earnings inequality is associated with higher income inequality, the force driving this result is the negative correlation between wealth dispersion and labor supply dispersion for a given level of ability. As a result, inequality in earnings partly offsets the inequality in capital incomes, and the greater earnings dispersion is, the lower income inequality becomes. In our tax exercise, a reduction in the capital income tax results in lower income inequality, while the opposite happens in the case of an increase in the capital income tax.

The fact that a reduction in the capital income tax reduces inequality seems to suggest that efficiency and distributional targets can simultaneously be obtained by setting the tax on capital income to zero, as proposed by Chamley (1986) in the context of a representative agent model. Such a result must be interpreted with care. If we set the tax on capital income to zero in our baseline case, output increases and income inequality falls from 0.676 to 0.417 (in the low inequality

\footnotetext{
${ }^{25}$ Using the "idiosyncratic shock model" to generate inequality, Domeij and Heathcote (2004) reach a similar qualitative conclusion regarding the effect of reducing capital income taxes, suggesting that changing the balance between capital and income taxes is likely to have very significant distributional consequences insofar as welfare inequality is concerned. Although space limitations preclude us from investigating welfare issues, it is a direction in which the present analysis could easily be extended, using the approach of García-Peñalosa and Turnovsky (2011).
} 
parameterization). However, this is a reduction in pre-tax inequality. Post-tax inequality is driven by both the effect on factor prices of changes in taxes and by the direct distributive effect of a lower tax on capital income. As long as capital is more unequally distributed than is labor income, the latter effect tends to increase inequality. It is possible to show that the direct effect dominates so that setting the capital income tax to zero results in higher post-tax income inequality, as is the case in a model with only capital heterogeneity; see García-Peñalosa and Turnovsky (2007) as well as the Appendix of the expanded version of this paper.

Lastly, inequality and mobility move together. In order to see this, consider the CobbDouglas case with $\eta=1.75$. The economy with the low tax on capital exhibits a level of income inequality of 0.601 and income mobility of 9.106. This last figure implies that agent $i$ will catch up with agent $j$ if their ability gap is $11 \%$ or more of their wealth gap. For the economy with a high capital tax, inequality is greater $(0.847)$ and poor agents need more ability in order to catch up in income - at least $19 \%$ of the wealth gap, corresponding to mobility of 5.281.

When we compare these results with those for the economy with fixed labor, presented in the lower panel, we find the three differences observed earlier: a much larger change in wealth inequality, higher levels of income inequality, and lower income mobility. The values of $\omega_{y}^{a}$ are much closer across the three tax experiments than in the case of flexible labor supply. The reason is simply that mobility is exclusively driven by factor price changes, while in our benchmark case there are labor supply responses the magnitude of which depends on the nature of the tax change.

We have undertaken some sensitivity analyses and find that the main results are robust to changes in parameter values (results available upon request). Inequality is very sensitive to the initial correlation between endowments, with a greater correlation resulting in both higher values of our measure of inequality and larger changes in response to shocks. Recall, however, that our measure of mobility is unaffected by distributional parameters since it computes the possibility of mobility rather than actual mobility. As such, it is affected by technological and preference parameters and by the nature of the shock, but not by the distributional parameters. In contrast, the elasticity of labor supply is a crucial parameter in determining distributional responses and, as indicated by Table 2, the potential for income mobility is strongly affected by this elasticity. A higher elasticity implies a 
stronger labor supply response of the ability-rich; as a result income inequality is lower and income mobility higher, and our robustness analysis indicates that mobility (inequality) is monotonically increasing (respectively, decreasing) with the value of $\eta$.

Lastly, our results also hold in a high-tax economy. For example, setting the two taxes and government expenditure to $44 \%$, a value close to that found in some of the high-tax European economies, we find qualitatively similar but stronger distributional effects of tax changes. Reducing the capital income tax by 5 percentage points (i.e. to $39 \%$ ) reduces income inequality in our benchmark case from 0.676 to 0.574 and yields a measure of income mobility of 10.066 . The reason for the stronger effect of a reduction of the same magnitude as those performed in Table 2 is that with a high level of taxes the distortion induced by a given change in the tax rate is larger and hence results in stronger labor supply responses.

\section{Conclusions}

In this paper we have studied wealth and income mobility in a Ramsey model with heterogeneous endowments of wealth and ability and an endogenous labor supply. In this framework, both inequality and mobility respond sharply to the macroeconomic environment, implying that changes in fundamentals or policy affect aggregate magnitudes, distribution, and the extent to which agents' position in the income distribution depends on their ability endowment.

Our numerical examples highlight the key role played by the elasticity of the labor supply. We found that although the percentage changes in inequality were roughly the same in the case of a high and a low elasticity, mobility differed substantially in the two cases, with a greater elasticity of labor being associated with a higher value of our mobility index. The reason for this difference lies in the role played by the endogenous labor supply. Wealthier people supply less labor while more able people supply more, and these two effects drive, together with changes in factor prices, the

possibility of income mobility. With a high elasticity of the labor supply, these responses are large, allowing the ability-rich to catch up more easily with the capital-rich and these results in greater mobility than for low values of this elasticity.

When we consider the effect of a reduction in government expenditure (and the required 
income tax rate), our analysis highlights the different behavior of inequality and mobility. The policy change results in much smaller changes in inequality than in the case of a productivity change, yet the degree of income mobility is about the same. The reason for these responses is that there is now a direct impact of tax changes on income and labor supply, which is absent in the case of a productivity change. The policy thus barely affects the overall degree of inequality yet there is substantial movement of individuals along the income distribution, so that, in the long-run, there is a stronger correlation between ability and income than before the policy change.

The joint analysis of inequality and mobility is important because not all forms of inequality are perceived in the same way. In particular, rewarding ability is often seen as a 'fairer' source of inequality than are differences in income due to initial wealth endowments; see Roemer (1998). As a result, one's perception of the fairness of an economy with a certain level of inequality will also depend on the degree of income mobility that is associated with that level of inequality. Our results emphasize that although substantial progress has been made in understanding the behavior of income distribution in macroeconomic models, focusing only on changes in an inequality index is insufficient to understand the implications of policy changes, since behind a given degree of inequality there may lay very different patterns of individual income mobility.

\section{Appendix: Proofs of Propositions 1, 2, and 3}

Proof of Proposition 1: Catch-up will occur if and only if $\hat{t}>0$, which since $\mu<0$, will be so if and only if

$$
0<\frac{\left(a_{i}-a_{j}\right)+\left(k_{i, 0}-k_{j, 0}\right) / \theta(0)}{\left(a_{i}-a_{j}\right)-\left(k_{i, 0}-k_{j, 0}\right)}<1
$$

In the case of a growing economy, i.e. when $\theta(0)>0$, these inequalities imply that for $k_{i, 0}>k_{j, 0}$ there will be catch up if and only if $-\Delta a \cdot \theta(0)>\Delta k$.

Proof of Proposition 2:At any point of time following a shock

$$
y_{i}(t)-y_{j}(t)=\varphi(t) \frac{1+\theta(t)}{1+\theta(0)}\left(k_{i, 0}-k_{j, 0}\right)+\left(1-\varphi(t) \frac{1+\theta(t)}{1+\theta(0)}\right)\left(a_{i}-a_{j}\right)
$$


implying that

$$
\begin{aligned}
& y_{i}(0)-y_{j}(0)=\varphi(0)\left(k_{i, 0}-k_{j, 0}\right)+(1-\varphi(0))\left(a_{i}-a_{j}\right) \\
& \tilde{y}_{i}-\tilde{y}_{j}=\frac{\tilde{\varphi}}{1+\theta(0)}\left(k_{i, 0}-k_{j, 0}\right)+\left(1-\frac{\tilde{\varphi}}{1+\theta(0)}\right)\left(a_{i}-a_{j}\right)
\end{aligned}
$$

Suppose first that $\Delta k>0$ and $\Delta a<0$. From (A.2,3), $y_{i}(0)-y_{j}(0)>0$ and $\tilde{y}_{i}<\tilde{y}_{j}$ hold if and only if (21a) holds. A necessary condition for (22a) to hold is $\varphi(0)>\tilde{\varphi} /(1+\theta(0))$. Consider now the case where $\Delta a>0$ and $\Delta k<0$. From (A.10), income mobility is possible if and only if (22b) holds. Moreover, satisfying (22b) requires $\varphi(0)<\tilde{\varphi} /(1+\theta(0))$.

Proof of Proposition 3: The time at which the income of two agents is the same, denoted $\bar{t}$, is defined by $\varphi(\bar{t})(1+\theta(\bar{t}))=[1+\theta(0)] \Delta a /(\Delta a-\Delta k)$, implying that there is catch-up if and only if $\bar{t}>0$. Combining this expression and (20) we see that $\varphi(\bar{t})(1+\theta(\bar{t}))=1+\theta(\hat{t})$. Since $\varphi(\bar{t})<1$ in a growing economy, this equality implies that $\theta(\bar{t})>\theta(\hat{t})$ which, given the definition of $\theta(t)$ in (13), in turn implies $\hat{t}>\bar{t}$.

\section{References}

Algan, Y., A. Cheron, J-O. Hairault, and F. Langot, 2003.Wealth effect on labor market transitions. Review of Economic Dynamics 6, 156-178.

Bourguignon, F., 1979. Decomposable income inequality measures, Econometrica 47, 901-920.

Burkhauser, R.V., S. Feng, S.P. Jenkins, and J. Larrimore, 2011. Estimating trends in US income inequality using the Current Population Survey: the importance of controlling for censoring. Journal of Economic Inequality 9, 393-415.

Caselli, F., and J. Ventura, 2000.A representative consumer theory of distribution. American Economic Review 90, 909-926.

Castañeda, A., J. Díaz-Giménez, and V. Rios-Rull, 1998. Exploring the income distribution business cycle dynamics. Journal of Monetary Economics 42, 93-130.

Chamley, C, 1986. Optimal Taxation of Capital Income in General Equilibrium with Infinite Lives, Econometrica, 54, 607-622. 
Chatterjee, S., 1994. Transitional dynamics and the distribution of wealth in a neoclassical growth model. Journal of Public Economics 54, 97-119.

Checchi, D., A. Ichino and A. Rustichini, 1999. More equal but less mobile? Education financing and intergenerational mobility in Italy and in the US. Journal of Public Economics 74, 351393.

Cheng, I-H.and E. French, 2000. The effect of the run-up in the stock market on labor supply. Federal Reserve Bank of Chicago Economic Perspectives 24, 48-65.

Cooley, T.F., 1995. Frontiers of Business Cycle Research. Princeton University Press, Princeton, N.J.

Coronado, J.L. and M. Perozek, 2003. Wealth effects and the consumption of leisure: Retirement decisions during the stock market boom of the 1990s. Board of Governors of the Federal Reserve System, Finance and Economics Discussion Series, 2003-20.

Díaz-Giménez, J., A. Glover, and J.V. Ríos-Rull, 2011. Facts on the distribution of earnings, income and wealth in the United States: 2007 Update. Federal Reserve Bank of Minneapolis Quarterly Review, 34:2-31.

Domeij, D. and J. Heathcote, 2004. On the distributional effects of reducing capital taxes. International Economic Review 45, 523-554.

García-Peñalosa, C. and E. Orgiazzi, 2013. Factor components of inequality: A cross-country study. Forthcoming Review of Income and Wealth.

García-Peñalosa, C. and S.J. Turnovsky, 2007. Growth, income inequality and fiscal policy: What are the relevant tradeoffs? Journal of Money, Credit, and Banking 39, 369-394.

García-Peñalosa, C. and S.J. Turnovsky, 2011. Taxation and income distribution dynamics in a neoclassical growth model. Journal of Money, Credit, and Banking 43, 1543-1577.

García-Peñalosa, C. and S.J. Turnovsky, 2012. Income Inequality, Mobility, and the Accumulation of Capital: The Role of Heterogeneous Labor Productivity. AMSE working paper 2012-16.

Gorman, W., 1953. Community preference fields. Econometrica 21, 63-80.

Guvenen, F., 2006.Reconciling conflicting evidence on the elasticity of intertemporal substitution: A macroeconomic perspective. Journal of Monetary Economics 53, 1451-1472. 
Holtz-Eakin, D., D. Joulfaian, and H.S. Rosen, 1993. The Carnegie conjecture: Some empirical evidence. Quarterly Journal of Economics 108, 413-435.

Jenkins, S.P., 1995. Accounting for inequality trends: Decomposition analyses for the UK, 1971-86. Economica 62, 29-63.

Krusell, P., and A. Smith, 1998.Income and wealth heterogeneity in the macroeconomy. Journal of Political Economy 106, 867-896.

Lee, C. I. and G. Solon, 2009. Trends in intergenerational income mobility. Review of Economics and Statistics91, 766-772.

Maliar, L. and S. Maliar, 2001. Heterogeneity in capital and skills in a neoclassical stochastic growth model. Journal of Economic Dynamics and Control 38, 635-654.

Maliar, L. and S. Maliar, 2003. The representative consumer in the neoclassical growth model with idiosyncratic shocks. Review of Economic Dynamics 6, 362-380.

Maliar, L., S. Maliar, and J. Mora, 2005. Income and wealth distributions along the business cycle: Implications from the neoclassical growth model. Topics in Macroeconomics 5(1), article 15.

McDaniel, C., 2007. Average tax rates on consumption, investment, labor and capital in the OECD 1953-2003. Mimeo, Arizona State University.

Piketty, T., 2000. Theories of persistent inequality and intergenerational mobility, in A.B. Atkinson and F. Bourguignon (eds.) Handbook of Income Distribution, Elsevier, Amsterdam, 429-476.

Piketty, T. 2011. On the long-run evolution of inheritance: France 1820-2050, Quarterly Journal of Economics 61, 1071-1131.

Piketty, T. and G. Zucman, 2013. Capital is back: Wealth-income ratios in rich countries 1700-2010, mimeo.

Roemer, J.,1998. Equality of opportunity, Harvard University Press, Cambridge.

Solon, G. 1999. Intergenerational mobility in the labor market. Handbook of Labor Economics, 3, 1761-1800.

Turnovsky, S.J. and C. García-Peñalosa, 2008. Distributional dynamics in a neoclassical growth model: The role of elastic labor supply. Journal of Economic Dynamics and Control 32, 1399-1431. 
Table 1: Increase in productivity

Baseline: Cobb-Douglas ( $\rho=0, \varepsilon=1$ ) and labor supply elasticity of $\eta=1.75$

\begin{tabular}{|c|c|c|c|c|c|c|c|c|c|c|c|}
\hline & Labor & $\tilde{K}$ & $\tilde{Y}$ & & & & & & & $\omega_{k}$ & $\omega_{y}^{a}$ \\
\hline $\begin{array}{l}\text { Base: } \\
A=1.5\end{array}$ & 0.277 & 1.804 & 0.771 & 14 & 28 & 1.422 & 2.845 & 0.676 & 1.352 & - & - \\
\hline$A=2$ & $\begin{array}{cc}L(0) & 0.280 \\
\tilde{L} & 0.277 \\
& (0 \%)\end{array}$ & $\begin{array}{c}2.771 \\
(+53.6 \%)\end{array}$ & $\begin{array}{c}1.184 \\
(+53.6 \%)\end{array}$ & $\begin{array}{c}13.575 \\
(-3.03 \%)\end{array}$ & $\begin{array}{c}27.151 \\
(-3.03 \%)\end{array}$ & $\begin{array}{c}1.386 \\
(-2.57 \%)\end{array}$ & $\begin{array}{c}2.771 \\
(-2.57 \%)\end{array}$ & $\begin{array}{c}0.669 \\
(-1.10 \%)\end{array}$ & $\begin{array}{c}1.338 \\
(-1.10 \%)\end{array}$ & 0.016 & 7.471 \\
\hline
\end{tabular}

High elasticity of substitution in production: $\rho=-0.13, \varepsilon=1.15$ (and labor supply elasticity of $\eta=1.75$ )

\begin{tabular}{|c|c|c|c|c|c|c|c|c|c|c|c|}
\hline & Labor & $\tilde{K}$ & $\tilde{Y}$ & & & $\tilde{\sigma}$ & $e^{2}$ & $\hat{o}$ & & $\omega_{k}$ & $\omega_{y}^{a}$ \\
\hline $\begin{array}{c}\text { Base: } \\
A=1.5\end{array}$ & 0.256 & 2.472 & 0.876 & 14 & 28 & 2.354 & 4.707 & 0.779 & 1.559 & - & - \\
\hline$A=2$ & $\begin{array}{cc}L(0) & 0.252 \\
\tilde{L} & 0.250 \\
(-2.18 \%)\end{array}$ & $\begin{array}{c}4.222 \\
(+70.8 \%)\end{array}$ & $\begin{array}{c}1.433 \\
(+63.6 \%)\end{array}$ & $\begin{array}{c}13.820 \\
(-1.28 \%)\end{array}$ & $\begin{array}{c}27.640 \\
(-1.28 \%)\end{array}$ & $\begin{array}{c}2.651 \\
(+12.6 \%)\end{array}$ & $\begin{array}{c}2.651 \\
(+12.6 \%)\end{array}$ & $\begin{array}{c}0.803 \\
(+3.11 \%)\end{array}$ & $\begin{array}{c}1.607 \\
(+3.11 \%)\end{array}$ & 0.007 & 5.662 \\
\hline
\end{tabular}

Inelastic labor supply: $\eta=0$ (and Cobb-Douglas production)

\begin{tabular}{|c|c|c|c|c|c|c|c|c|c|c|c|}
\hline \multirow{2}{*}{$\begin{array}{c}\text { Base: } \\
A=1.5\end{array}$} & \multirow{2}{*}{$\begin{array}{c}\text { Labor } \\
\mathbf{0 . 2 7 7}\end{array}$} & \multirow{2}{*}{$\begin{array}{c}\tilde{K} \\
\mathbf{1 . 8 0 4}\end{array}$} & \multirow{2}{*}{$\begin{array}{c}\tilde{Y} \\
\mathbf{0 . 7 7 1}\end{array}$} & \multicolumn{2}{|c|}{$\tilde{\sigma}_{k}^{2}$} & \multicolumn{2}{|c|}{$\tilde{\sigma}_{e}^{2}$} & \multicolumn{2}{|c|}{$\tilde{\sigma}_{y}^{2}$} & \multirow{2}{*}{$\begin{array}{c}\omega_{k} \\
-\end{array}$} & \multirow{2}{*}{$\begin{array}{c}\omega_{y}^{a} \\
-\end{array}$} \\
\hline & & & & 14 & 28 & 0.400 & 0.800 & 2.049 & 4.099 & & \\
\hline$A=2$ & 0.277 & $\begin{array}{c}2.772 \\
(+53.6 \%)\end{array}$ & $\begin{array}{c}1.185 \\
(+53.6 \%)\end{array}$ & $\begin{array}{c}9.581 \\
(-31.6 \%)\end{array}$ & $\begin{array}{c}19.161 \\
(-31.6 \%)\end{array}$ & 0.400 & 0.800 & $\begin{array}{c}1.537 \\
(-25.0 \%)\end{array}$ & $\begin{array}{c}3.074 \\
(-25.5 \%)\end{array}$ & 0.225 & 2.711 \\
\hline
\end{tabular}




\section{Table 2: Fiscal changes}

Baseline: Cobb-Douglas and elastic labor ( $\rho=0, \varepsilon=1, \eta=1.75$ )

\begin{tabular}{|c|c|c|c|c|c|c|c|c|c|c|c|c|}
\hline \multirow[b]{2}{*}{ Base: $\tau_{w}=\tau_{k}=g=0.22$} & \multirow{2}{*}{\multicolumn{2}{|c|}{$\begin{array}{l}\text { Labor } \\
\mathbf{0 . 2 7 7} \\
\end{array}$}} & \multirow{2}{*}{$\begin{array}{c}\tilde{K} \\
1.804 \\
\end{array}$} & \multirow{2}{*}{$\begin{array}{c}\tilde{Y} \\
\mathbf{0 . 7 7 1} \\
\end{array}$} & \multicolumn{2}{|c|}{$\tilde{\sigma}_{k}^{2}$} & \multicolumn{2}{|c|}{$\tilde{\sigma}_{e}^{2}$} & \multicolumn{2}{|c|}{$\tilde{\sigma}_{y}^{2}$} & \multirow{2}{*}{$\begin{array}{l}\omega_{k} \\
- \\
-\end{array}$} & \multirow{2}{*}{$\begin{array}{c}\omega_{y}^{a} \\
-\end{array}$} \\
\hline & & & & & 14 & 28 & 1.422 & 2.845 & 0.676 & 1.352 & & \\
\hline $\begin{array}{l}\text { Expenditure/tax reduction } \\
\qquad \tau_{w}=\tau_{k}=g=0.17\end{array}$ & $\begin{array}{l}L(0) \\
\tilde{L}\end{array}$ & $\begin{array}{l}0.278 \\
0.277\end{array}$ & 1.979 & 0.795 & 13.890 & 27.781 & 1.413 & 2.826 & 0.674 & 1.349 & 0.004 & 7.368 \\
\hline $\begin{array}{c}\text { Shift in the tax burden: } \\
\text { Reduction in capital income tax } \\
\tau_{k}=0.17, \tau_{w}=0.245, g=0.22\end{array}$ & $\begin{array}{l}L(0) \\
\tilde{L}\end{array}$ & $\begin{array}{l}0.271 \\
0.270\end{array}$ & 1.933 & 0.776 & 13.920 & 27.840 & 1.650 & 3.304 & 0.601 & 1.202 & 0.003 & 9.106 \\
\hline $\begin{array}{c}\text { Shift in the tax burden: } \\
\text { Reduction in labor income tax } \\
\tau_{k}=0.322, \tau_{w}=0.17, g=0.22\end{array}$ & $\begin{array}{l}L(0) \\
\tilde{L}\end{array}$ & $\begin{array}{l}0.288 \\
0.289\end{array}$ & 1.536 & 0.753 & 14.240 & 28.489 & 1.066 & 2.122 & 0.847 & 1.699 & -0.009 & 5.281 \\
\hline
\end{tabular}

Inelastic labor and Cobb-Douglas $(\rho=0, \varepsilon=1, \eta=0)$

\begin{tabular}{|c|c|c|c|c|c|c|c|c|c|c|c|}
\hline \multirow[b]{2}{*}{ Base: $\tau_{w}=\tau_{k}=g=0.22$} & \multirow{2}{*}{$\begin{array}{l}\text { Labor } \\
\mathbf{0 . 2 7 7} \\
\end{array}$} & \multirow{2}{*}{$\begin{array}{c}\tilde{K} \\
\mathbf{1 . 8 0 4} \\
\end{array}$} & \multirow{2}{*}{$\begin{array}{c}\tilde{Y} \\
\mathbf{0 . 7 7 1} \\
\end{array}$} & \multicolumn{2}{|c|}{$\tilde{\sigma}_{k}^{2}$} & \multicolumn{2}{|c|}{$\tilde{\sigma}_{e}^{2}$} & \multicolumn{2}{|c|}{$\tilde{\sigma}_{y}^{2}$} & \multirow{2}{*}{$\begin{array}{l}\omega_{k} \\
- \\
-\end{array}$} & \multirow{2}{*}{$\begin{array}{c}\omega_{y}^{a} \\
-\end{array}$} \\
\hline & & & & 14 & 28 & 0.400 & 0.800 & 2.049 & 4.099 & & \\
\hline $\begin{array}{l}\text { Expenditure/tax reduction } \\
\qquad \tau_{w}=\tau_{k}=g=0.17\end{array}$ & $\begin{array}{ll}L(0) & 0.277 \\
\tilde{L} & 0.277\end{array}$ & 1.980 & 0.795 & 12.985 & 25.970 & 0.400 & 0.800 & 1.932 & 3.865 & 0.041 & 2.154 \\
\hline $\begin{array}{c}\text { Shift in the tax burden: } \\
\text { Reduction in capital income tax } \\
\tau_{k}=0.17, \tau_{w}=0.245, g=0.22\end{array}$ & $\begin{array}{ll}L(0) & 0.277 \\
\tilde{L} & 0.277\end{array}$ & 1.980 & 0.795 & 13.025 & 26.050 & 0.400 & 0.800 & 1.937 & 3.874 & 0.039 & 2.149 \\
\hline $\begin{array}{c}\text { Shift in the tax burden: } \\
\text { Reduction in labor income tax } \\
\tau_{k}=0.321, \tau_{w}=0.17, g=0.22\end{array}$ & $\begin{array}{ll}L(0) & 0.277 \\
\tilde{L} & 0.277\end{array}$ & 1.465 & 0.720 & 16.591 & 33.183 & 0.400 & 0.800 & 2.347 & 4.695 & -0.086 & 1.771 \\
\hline
\end{tabular}

